\title{
Práticas de atividade física: uma análise da motivação e satisfação dos policiais militares de João Pessoa
}

\section{RESUMO}

O presente estudo tem como objetivo analisar os aspectos motivacionais e de satisfação nas práticas de atividades físicas dos policiais militares. Do ponto de vista metodológico este estudo contempla uma pesquisa de natureza qualitativa - descritiva e transversal, os dados foram obtidos através de um questionário semi-estruturado, sendo analisados de forma qualitativa e quantitativa, através da análise de conteúdo e estatística percentual simples. Esta pesquisa foi realizada com 32 policiais militares da ativa e guarda da reserva, de ambos os sexos, pertencentes ao $5^{\circ}$ Batalhão de Polícia Militar do estado da Paraíba. Os resultados obtidos sugerem que a maioria dos policiais são adeptos a alguma prática de atividade física, foram observados a predominância de fatores intrínsecos na motivação para a realização destas práticas, os principais citados são saúde, bem-estar, qualidade de vida, estética e condicionamento físico para atuação profissional.

PALAVRAS-CHAVE: Educação física; Atividade física; Motivação; Saúde; Policial militar 


\title{
Physical activity practices: an analysis of the motivation and satisfaction of the military police in João Pessoa
}

\begin{abstract}
This study aims to analyze the motivational and satisfaction aspects in the physical activity practices of military police officers. From a methodological point of view, this study includes a qualitative - descriptive and transversal research, the data were obtained through a semi-structured questionnaire, being analyzed in a qualitative and quantitative way, through content analysis and simple percentage statistics. This research was carried out with 32 military police officers of the active and guard of the reserve, of both sexes, belonging to the $5^{\text {th }}$ Military Police Battalion of the state of Paraíba. The results obtained suggest that most police officers are adept at some physical activity practice, the predominance of intrinsic factors in the motivation to perform these practices was observed, the main ones mentioned being health, well-being, quality of life, aesthetics and physical conditioning for professional performance.
\end{abstract}

KEYWORDS: Physical education; Physical activity; Motivation; Health; Military police

\section{Prácticas de actividad física: un análisis de la motivación y la satisfacción de la policía militar en João Pessoa}

\section{RESUMEN}

Este estudio tiene como objetivo analizar los aspectos de motivación y satisfacción en las prácticas de actividad física de los oficiales de la policía militar. Desde un punto de vista metodológico, este estudio incluye una investigación cualitativa - descriptiva y transversal, los datos se obtuvieron a través de un cuestionario semiestructurado, analizándose de manera cualitativa y cuantitativa, a través de análisis de contenido y estadísticas de porcentajes simples. Esta investigación se realizó con 32 policías militares del activo y guardia de la reserva, de ambos sexos, pertenecientes al $5^{\circ}$ Batallón de la Policía Militar del estado de Paraíba. Los resultados obtenidos sugieren que la mayoría de los oficiales de policía son expertos en alguna práctica de actividad física, se observó el predominio de factores intrínsecos en la motivación para realizar estas prácticas, los principales mencionados fueron la salud, el bienestar, la calidad de vida, la estética y el acondicionamiento físico para un desempeño profesional.

PALABRAS CLAVE: Educación física; Actividad física; Motivación; Salud; Policia militar 


\section{INTRODUÇÃO}

Alguns fatores como o sedentarismo, doenças crônico-degenerativas, estresse, depressão e obesidade são reflexos de uma abstenção da prática de AF, tornando essas patologias cada vez mais frequentes e acometendo cada vez mais precocemente a população brasileira (PITANGA, 2004). Os profissionais que atuam na área de segurança pública enfrentam as mesmas problemáticas com relação as doenças mórbidas, posto que, a prática de AF se faz ainda mais necessária para a atuação profissional, uma vez que nesta atividade laboral o corpo torna-se uma ferramenta de trabalho que deve ser constantemente preparada para a necessidade que o serviço policial impõe (SILVA, 2015).

Caspersen e colaboradores (1985), definem atividade física como qualquer movimento realizado pelo corpo através da ação concêntrica ou excêntrica da musculatura esquelética que resulte em um gasto energético superior aos períodos de repouso. Conceituando também o exercício físico (EF), como a realização da AF de forma planejada, sistematizada, estruturada, de caráter repetitivo e contínuo tendo como objetivo a melhoria e a manutenção de pelo menos um componente da aptidão física.

Contudo, para a prática de uma AF sistematizada, ou seja, a realização de exercícios físicos de forma planejada e contínua durante um lapso temporal é necessário alguma forma de motivação, aliás, para realizar qualquer ação que mova o ser humano para fora da zona de conforto o fator motivacional é imprescindível.

De acordo com Schwaab (2014), a motivação pode ser observada como fator resultante de duas perspectivas distintas de estímulos, tipificando a motivação em dois grupos, caracterizando-as como motivação intrínseca e motivação extrínseca.

Ao abordar a temática, Bergamini (1997) relata que a motivação intrínseca está ligada à capacidade do indivíduo em realizar a atividade pelo resultado ou satisfação que ela produz, ou seja, desenvolver uma determinada atividade pela recompensa inerente desta própria atividade. Podemos usar como exemplo para essa categoria de motivação o praticante de caminhada que faz uso do exercício caminhar de forma sistematizada e com intensidade moderada para obter uma sensação de auto realização ou alegria pessoal por ter realizado a atividade, neste contexto o resultado esperado da atividade é inerente à própria atividade gerando uma satisfação espontânea no praticante baseada no seu próprio desempenho. Já a motivação extrínseca dar-se-á por fatores externos também denominados ambientais, podendo manifestar-se como recompensas ou castigos que impulsionem o indivíduo à realização de determinadas tarefas que não são atraentes ou prazerosas para a execução de forma espontânea, com intuito de atingir determinado objetivo. 
A respeito da Teoria Hierárquica das Necessidades Humanas, Faria (2004, p. 6) descreve que "todo comportamento humano gira em torno de satisfazer necessidades. Uma necessidade insatisfeita constitui o ponto de partida no processo da motivação [...] forçando-o a engajar-se em alguma espécie de comportamento para satisfazer essa necessidade".

Tendo como base a teoria proposta, compreendemos que as pessoas estão em um contínuo processo de desenvolvimento em busca de satisfazer suas necessidades, partindo das mais básicas para as mais complexas. Do mesmo modo, Marras (2010) acrescenta:

Todas as pessoas têm necessidades, cada uma delas com peculiaridades e intensidades distintas. Isso faz com que elas sempre estejam tentando satisfazer essas necessidades. A motivação é força motriz que alavanca as pessoas a buscarem a satisfação. Enquanto perdura a situação, perdura a motivação. Ao satisfazer a necessidade, acaba a motivação. No mesmo instante, contudo, nasce uma nova necessidade e, por via de consequência, uma nova força motriz impele o indivíduo a novamente buscar outra satisfação. Instala-se assim um moto-contínuo um looping infindável, que forma o movimento dialético motivacional (MARRAS, 2010, p.34).

Sabemos que a motivação é imprescindível para a prática de AF, e que esta por sua vez promove uma série de benefícios para quem estabelece um hábito na realização de tais atividades, desencadeando uma melhor qualidade de vida (ZAMAI; BANKOFF, 2013). Segundo Silva (2015, p.125), "sobretudo quando tratamos de policiais militares, possuidores de uma condição de trabalho diferenciada dos demais trabalhadores e consequentemente expostos a situações de risco que envolvem violência, longas jornadas de trabalho, estresse entre outros". Neste sentido:

Muitas vezes, não é dada a devida importância à prática da atividade física pelo ser humano, em especial, pelos policiais militares que, pela característica do serviço, não muito raramente, têm que realizar esforço físico além daquele habitual e, nesse momento, aparecem a fadiga, o cansaço repentino, levando até mesmo ao desmaio, podendo tais sintomas de cansaço ser minimizados caso exista uma frequência na prática de atividade física (SILVA, 2015, p.125).

A literatura apresentada por Kotler (2006), destaca que a satisfação/insatisfação é resultado de um processo de avaliação ou julgamento de uma experiência particular, através de parâmetros individuais e subjetivos que determinam o cumprimento das expectativas e desejos pessoais deste indivíduo. Neste sentido a satisfação/insatisfação pode ser entendida como resultado de um conjunto de fatores que estão interligados, podendo representar o estopim para o início de uma prática ou o motivo para abstenção desta.

Sendo assim, observamos que fatores como a necessidade de passar a maior parte de uma jornada de trabalho de 24 horas sentado em uma viatura, realizando o policiamento Rádio patrulha ${ }^{1}$, 
aliado aos preocupantes níveis de stress gerado pela própria profissão, bem como a iminente situação de risco vivenciada durante a jornada de trabalho, levam à necessidade da prática de $\mathrm{AF}$ como subterfúgio para os policiais superarem as adversidades impostas pela sua rotina de trabalho e manterem um estilo de vida saudável, refletindo diretamente e positivamente nos serviços prestados à sociedade.

Pretende-se através deste estudo produzir um arcabouço de informações acerca das características e comportamentos motivacionais dos sujeitos da pesquisa, contribuindo para a elaboração de planos e medidas que influenciarão no aumento da prática de AF pelos profissionais desta e de outras corporações, proporcionando uma vida com mais qualidade e um profissional mais apto a realizar as suas funções.

Portanto, considerando o exposto, o presente estudo tem como objetivo geral analisar os aspectos motivacionais e de satisfação nas práticas de atividades físicas dos policiais militares, para tal elencou-se como objetivos específicos: verificar os aspectos socioculturais e demográficos dos sujeitos envolvidos nesta pesquisa; identificar os hábitos da prática de AF dos policiais militares; descrever as características motivacionais relacionadas às práticas de $\mathrm{AF}$ dos policiais militares $\mathrm{e}$ analisar os aspectos de satisfação e insatisfação quanto as práticas de AF e imagem corporal dos policiais militares.

\section{MATERIAIS E MÉTODOS}

Do ponto de vista metodológico, este estudo contemplou uma pesquisa de natureza qualitativa, visto que buscou analisar os aspectos motivacionais e de satisfação nas práticas de atividades físicas do público-alvo pesquisado. Além disso, o tipo do estudo se apresenta de forma descritiva, tendo em vista que buscou descrever as características de determinada população ou fenômenos, utilizando técnicas padronizadas de levantamento dos dados. Já como procedimentos técnicos de análise adotou-se a análise do conteúdo e quanto ao desenvolvimento no tempo tratouse de uma pesquisa transversal também denominada seccional (GERHARDT; SILVEIRA, 2009; FONTELLES et al., 2009).

A amostra intencional não probabilística, foi composta por 32 policiais militares, sendo 31 do sexo masculino, pertencentes à $1^{\mathrm{a}}$ Cia de Rádio Patrulhamento do $5^{\mathrm{o}}$ Batalhão de Polícia Militar, localizado na cidade de João Pessoa-PB, que se enquadraram nos seguintes critérios de inclusão: ser policial militar na condição da ativa ou guarda da reserva; ser voluntário a participar do presente estudo.

${ }^{1}$ Modalidade de policiamento ostensivo, realizada por homens, mulheres e materiais (viaturas equipadas com rádio) em permanente contato com um centro integrado de operações (CIOP). (Grifo nosso). 
Os dados relativos aos hábitos de prática de $\mathrm{AF}$ bem como às características motivacionais dos voluntários desta pesquisa, foram obtidos por intermédio do instrumento da pesquisa, um questionário semiestruturado, construído pelo autor e validado por professores e membros do grupo de estudo LEPAFS (Laboratório de Estudos e Pesquisas em Atividade Física e Saúde) da Universidade Federal da Paraíba, sendo composto por questões abertas e fechadas. O questionário em questão foi aplicado momentos antes do início da jornada de trabalho, com duração média de 25 minutos, nas dependências da própria companhia de policiamento, entre os dias 14 e 19 do mês de outubro de 2019.

Os dados obtidos nesta pesquisa foram analisados nos aspectos qualitativos e quantitativos, através da análise de conteúdo e estatística percentual simples, para tal tomamos como base Bardin (1977), que caracteriza a organização da análise do conteúdo dividindo-a em três fases: pré-análise; exploração do material; o tratamento dos resultados (inferência e a interpretação). Neste sentido:

Os resultados brutos são tratados de maneira a serem significativos («falantes») e válidos. Operações estatísticas simples (percentagens), ou mais complexas, análise factorial (sic), permitem estabelecer quadros de resultados, diagramas, figuras e modelos, os quais condensam e põem em relevo as informações fornecidas pela análise [...] O analista, tendo a sua disposição ·resultados significativos e fiéis, pode então propor inferências e adiantar interpretações a propósito dos objetivos (sic) previstos, ou que digam respeito a outras descobertas inesperadas (BARDIN, 1977, p.101).

Para o processamento e análise dos dados, este estudo foi sistematizado em quatro categorias sendo elas: categoria sociométrica; motivação; hábitos de atividade física e satisfação. A escolha de tais categorias viabilizou-se por meio das respostas obtidas através do instrumento desta pesquisa e foi fundamentada no objeto da investigação tendo a prática de AF e suas determinantes como fator preponderante para a compreensão dos aspectos motivacionais e da satisfação do público alvo.

O presente estudo intitulado Práticas de atividade física: uma análise da motivação e satisfação dos policiais militares de João Pessoa com o CAAE: 21625219.9.0000.8069, foi aprovado pelo Comitê de Ética do Centro de Ciências Médicas da Universidade Federal da Paraíba, através do Parecer $n^{\circ}$ : 3.686.896, seguindo de acordo com a norma 466\2012 CNS/CONEP, que diz respeito à condição de dignidade e autonomia humana em relação a pesquisas com seres humanos através do consentimento e assinatura do termo de aceitação livre e esclarecido por parte dos participantes desta pesquisa. 


\section{RESULTADOS E DISCUSSÕES}

\section{Caracterização Sociométrica dos Participantes}

Com base nas respostas obtidas através do questionário utilizado nesta pesquisa, podemos descrever as características sociométricas dos participantes da seguinte forma: observamos que $\mathrm{n}$ $=31(97 \%)$ dos participantes são militares do sexo masculino, este dado reflete a carência do serviço operacional de militares do sexo feminino², tendo em vista a importância tanto para o serviço policial (aspectos procedimentais), quanto nos aspectos social e representativo das mulheres nesta função. Tal diferença nos quantitativos do efetivo muito provavelmente é fruto da diferença na oferta/cotas de vagas entre os sexos para concursos desta natureza no estado da Paraíba. Sobre a segregação sexual da ocupação das vagas, segundo Yannoulas (2013):

Persistem as desigualdades inerentes à divisão sexual do trabalho; tanto em nível horizontal, vista nas restritas ocupações das mulheres, geralmente derivadas das funções de reprodução social e cultural, como em nível vertical, refletida na desvantagem de salários, carreira e condições de trabalho das mulheres em relação aos homens (YANNOULAS, 2013, p.140).

Neste sentido, em uma corporação tal qual a polícia militar, onde a estrutura funcional historicamente é caracterizada por uma ampla dominação masculina, há uma longa caminhada de desconstrução de paradigmas para a inserção equitativa das mulheres nos quadros de efetivo desta organização, não apenas na execução dos serviços administrativos/gerenciais como também nos serviços operacionais de policiamento ostensivo.

Quanto à idade percebemos que $n=14(44 \%)$ da amostra encontra-se numa faixa etária entre 36 e 45 anos, enquanto $n=11$ (34\%) entre 26 e 35, já um n=4 (13\%) estão numa faixa etária entre 46 e 55 anos e $n=3(9 \%)$ possuem mais que 55 anos.

Com relação ao grau hierárquico, ou seja, posto ou graduação que o militar ocupa na corporação Policia Militar, foi possível observar que $n=15$ (47\%) do efetivo policial é composto pelos Cabos, $n=8$ (25\%) são Sargentos, enquanto $n=7$ (22\%) são Soldados, $n=1$ (3\%) Capitães e $\mathrm{n}=1(3 \%)$ Tenente.

No que se refere à renda salarial a maioria dos entrevistados $n=18(56 \%)$ informou possuir renda de 4 a 5 salários mínimos, enquanto $n=12$ (38\%) recebem de 1 a 3 salários e $n=2$ (6\%) informou receber mais que 8 salários mínimos.

\footnotetext{
${ }^{2}$ Dados obtidos no Relatório da Diretoria de Gestão de Pessoas da Corporação Polícia Militar da Paraíba, referentes a novembro 2019, revelam que diante de um efetivo de 9.202 militares da ativa, apenas 777 são militares do sexo feminino, o que representa um percentil de pouco mais de $8 \%$.
} 
Quanto à modalidade de trabalho exercida por esses militares, foi observado que $n=24$ (62\%) das respostas afirmam que a rotina profissional é exercida no rádio patrulhamento, já $\mathrm{n}=6$ (15\%) destacam o setor administrativocomo local de trabalho, sendo responsáveis pelo serviço burocrático de escala de serviço, envio e recebimento de ofícios, entre outros. Um n=5 (13\%) afirmaram realizar serviços de guarda ao aquartelamento, realizando a segurança do patrimônio e material bélico. Enquanto $\mathrm{n}=4(10 \%)$ destacam a modalidade ciclo patrulhamento, referente ao policiamento com apoio de bicicletas. É importante salientar que o militar pode atuar em mais de uma modalidade de trabalho, através dos plantões extras.

No que se refere à escala de serviço, cada modalidade de trabalho incide em uma escala diferenciada de horas trabalhadas por horas de folga, neste sentido observamos que $n=21(81 \%)$ das respostas indicam a escala 24 horas de serviço por 72 de folga como escala de serviço predominante, sendo esta a escala referente ao serviço operacional de rádio patrulha. É importante salientar que há uma constante prática permitida por lei, na qual o policial militar pode realizar plantões extras de serviço o que resulta na diminuição da sua carga horária de folga. Observamos que $n=3(10 \%)$ alegou trabalhar 6 horas diárias de segunda à sexta configurando a escala do serviço no expediente administrativo. Enquanto n=2 (6\%) alegou trabalhar 12 horas e folgar 12, reflexo dos plantões extras e $n=1$ (3\%) informou trabalhar 24 horas e folgar 96 , esta escala é referente ao serviço realizado pelo oficial que coordena e fiscaliza o rádio patrulhamento.

\section{Motivação para a Prática de Atividades Físicas}

Com base nas respostas obtidas por meio do questionário, foi possível concluir que $n=24$ (75\%) dos policiais militares se consideram motivados para a prática de $A F$, enquanto $n=8(25 \%)$ afirmaram que não se sentem motivados. Compreendemos que a motivação é fator preponderante para a adesão e permanência nas práticas de AF, sobretudo quando não há um caráter obrigatório para a realização destas atividades, fazendo necessário a percepção individual dos policiais acerca da importância na realização de tais práticas.

A motivação pode ser considerada o gatilho que impulsiona o indivíduo a movimentar-se aspirando metas e objetivos pré-estabelecidos (BERGAMINI, 1997). Desta forma, foi importante para este estudo questionar a existência da motivação para a prática de $\mathrm{AF}$, bem como indagar por quais fatores o indivíduo se sente motivado para tal atividade. 
Gráfico 1: Fatores motivacionais para a prática de atividades físicas.

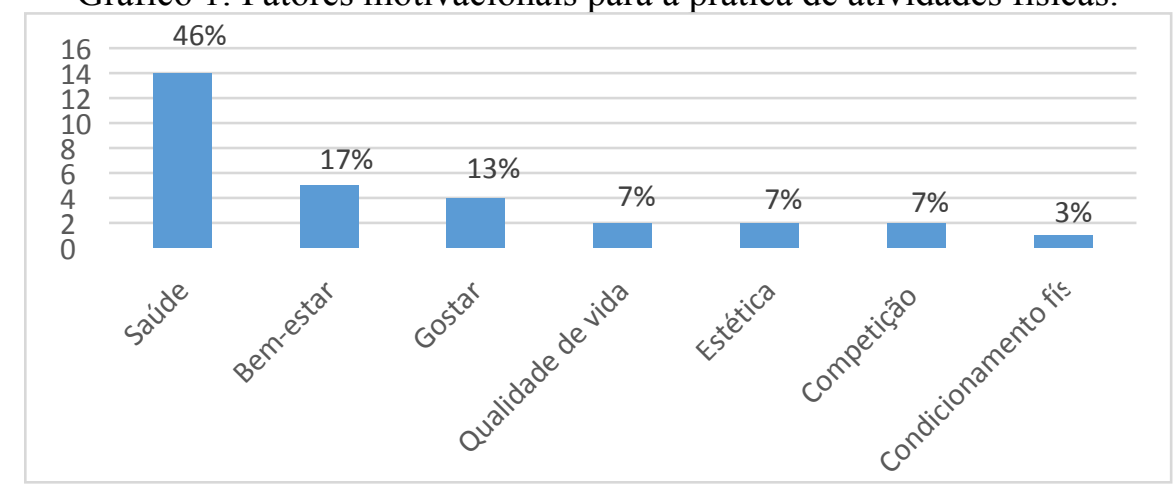

Fonte: Questionário da pesquisa, 2019.

Através do questionamento realizado acerca da justificativa sobre a autopercepção dos militares com relação à motivação para a prática de AF (Gráfico 1), observou-se a recorrência do termo saúdecom $n=14(46 \%)$ das respostas, como fator motivacional para a execução de AF. Neste sentido, relacionando a saúde com a profissão militar, reiteramos as argumentações de Silva e colaboradores (2014):

A carreira do policial militar pode contribuir para um quadro nada saudável, pois esses profissionais lidam com situações extremas no dia-a-dia de sua atividade laboral, sendo sujeitados a constantes mudanças psicofisiológicas. Dessa forma, a rotina de trabalho assim como os hábitos adotados, podem ser fatores determinantes no surgimento de diversos fatores de risco para a saúde dos policiais militares, desencadeando uma doença crônica (SILVA et al., 2014, p.682).

Para a categoria policial militar, a atividade física é algo intrínseco à profissão, podendo se perceber esta ligação explicitamente durante as etapas do próprio concurso público para o ingresso na carreira, onde para adentrar efetivamente na corporação o indivíduo necessita passar por uma série de testes físicos eliminatórios e concluir um curso de formação, no qual é realizado uma rotina diária de atividades físicas obrigatórias, como forma de doutrinar o corpo e manter-se apto fisicamente para as demandas provenientes da própria profissão. A respeito da doutrinação exigida para a formação militar, bem como a transformação e ou modificação da conduta do indivíduo na preparação para sua atuação, Foucault (1987) afirma que:

“...em qualquer sociedade, o corpo está preso no interior de poderes muito apertados, que lhe impõem limitações, proibições ou obrigações... Esses métodos que permitem o controle minucioso das operações do corpo, que realizam a 
sujeição constante de suas forças e lhes impõem uma relação de docilidadeutilidade, são o que podemos chamar as disciplinas" (FOUCAULT, 1987, p.163).

Podemos perceber, através dos dados obtidos, que a saúde é o fator motivacional que mais estimula a prática da AF entre os policiais militares, o que é um fato positivo, pois identificamos a percepção dos pesquisados na relação proporcional de importância exercida entre a AF e a saúde, como também observamos a preocupação em manter-se saudável não somente para cumprir seu ofício policial, mas para estar presente em seu âmbito familiar ao término da sua jornada de trabalho.

Por meio da inferência e interpretação dos dados levantados no questionário utilizado, observamos que o motivo mais incisivo para a prática de AF dos sujeitos desta pesquisa é a promoção da saúde, o que contribui diretamente na qualidade de vida dos participantes, seja através dos seus efeitos antropométricos e neuromusculares ou efeitos metabólicos e psicológicos (ZAMAI; BANKOFF, 2013). Tais afirmações tornam-se perceptíveis nas seguintes falas:

[...]Amo fazer atividade física, pois mediante esta prática ajuda a me manter saudável e com excelente disposição e com a mente sã, pronto para qualquer finalidade[...] (Suj. 26).

[...]Penso na minha saúde em primeiro lugar e por questão de vaidade, ter um corpo definido[...] (Suj. 27).

[...]Manter a qualidade de vida e uma saúde excelente[...] (Suj. 29).

Sobre os "não-motivados" para a prática encontramos um n=8 (25\%) da amostra que relatou não estar motivado para a prática de $\mathrm{AF}$, mesmo quando questionados sobre a importância desta prática para a profissão militar. Entre as respostas obtidas destacamos:

[...]Acho que minha falta de motivação é não ter alguém que vá junto comigo[...] (Suj.15).

[...]Cansaço, falta de energia[...] (Suj. 4)

[...]Falta de tempo[...] (Suj. 5)

[...]A instituição de trabalho PM-PB não motiva[...] (Suj. 17).

Observamos a existência de fatores intrínsecos e extrínsecos quanto a não motivação para a prática de atividades físicas, ou seja, podemos afirmar que em uma parcela dos sujeitos há uma predisposição para a prática de $\mathrm{AF}$, porém fatores alheios a sua vontade os fazem abster desta prática, como por exemplo a falta de estímulos proveniente do seu âmbito laboral.

Neste sentido, esta pesquisa corrobora com os estudos realizados por Jesus e Jesus(2012),no que diz respeito as barreiras para a prática de AF de policiais militares, ao destacar que, aspectos como a falta de tempo resultante da jornada de trabalho e/ou de estudos, compromissos familiares, as tarefas domiciliares, a falta de companhia e a falta de uma política de promoçãoda prática de 
atividades físicas, esportivas e de lazer na Polícia Militar são os principais fatores coibentes da adesão à prática de AF entre os indivíduos estudados.

É importante destacar que dentre os que responderam não se julgar motivado para a prática de $\mathrm{AF}, \mathrm{n}=8(25 \%)$, existem aqueles que realizam tais atividades $\mathrm{n}=4$, este comportamento pode ser compreendido como a assimilação por parte dos policiais da extrema importância em manter-se numa rotina de exercícios e AF, com intuito de aprimorar as suas capacidades físicas e adquirir um estilo de vida mais saudável, mesmo não se sentindo atraído pela realização de tais práticas. Outros fatores também podem exercer influência nesta decisão, como a existência de tratamentos que envolvam a AF como forma de prevenção/reabilitação de algumas patologias ou tratando-se do âmbito militar a obrigatoriedade regulamentada da prática de AF, esta última, não vindo a ser o caso dos militares entrevistados.

\section{Hábitos de Prática das Atividades Físicas}

Uma prática regular de AF aliada a hábitos saudáveis de alimentação e uma boa qualidade do sono, são essenciais para o estabelecimento de um estilo de vida saudável, refletindo numa melhor qualidade de vida dos praticantes (ZAMAI; BANKOFF, 2013). Desta forma, nos propusemos a identificar os hábitos de prática dos sujeitos da pesquisa e a implicação desta na rotina laboral dos policiais militares.

Gráfico 2: Demonstrativo das modalidades de prática das atividades física.

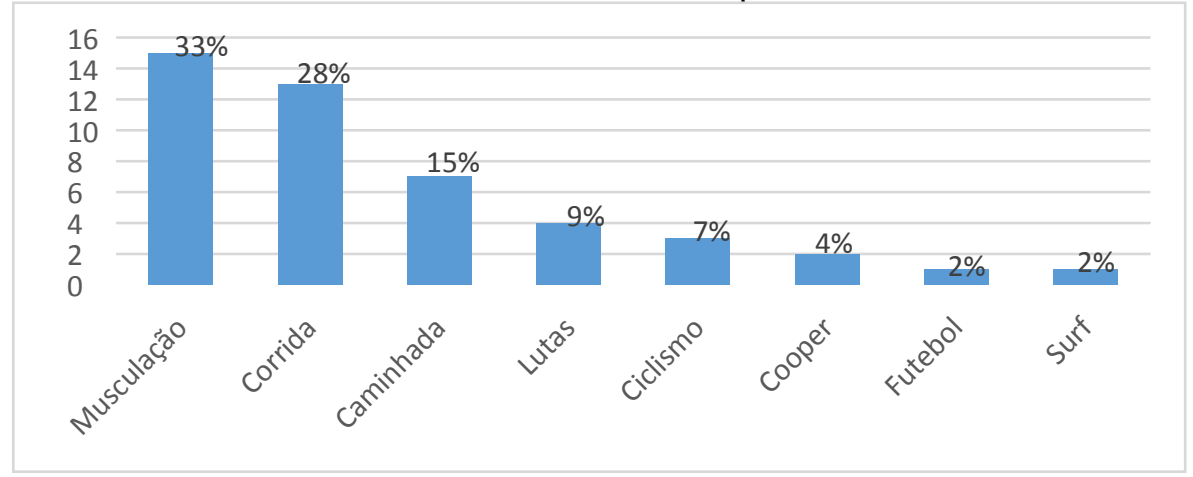

Fonte: Questionário da pesquisa, 2019.

Diante das informações obtidas nos questionários e através do gráfico 2, é possível afirmar que a maioria, ou seja, $n=28$ (87\%) dos sujeitos investigados são adeptos de alguma prática de atividade física.Neste sentido, as características que envolvem a escolha destas modalidades de $\mathrm{AF}$ por parte dos policiais, exercem uma contribuição importante nos quantitativos apresentados. Razões como a manutenção da saúde, o gostarou ter afinidade pela atividade, obem-estar, a facilidade para a realização da prática, a estética e o condicionamento físico voltado para as 
atividades policiais, caracterizam-se como fatores primordiais para a realização e permanência de forma contínua nas modalidades descritas pelos participantes. Tal afirmação contextualiza-se nas seguintes premissas:

[...]Para manter meu condicionamento físico, ajuda a me manter saudável com confiança e auto-estima [...] (Suj. 26).

[...]O Jiu-Jitsu, para que as técnicas auxiliem no trabalho. E as demais práticas são realizadas por afinidade e por me sentir mais feliz depois da execução[...] (Suj. 32).

[...]Por ser um esporte livre e sem muitas exigências, a corrida se torna sendo o esporte mais praticado pelas pessoas[...] (Suj. 29).

[...]Preparo pessoal, saúde e atividades policiais[...] (Suj. 3).

Deste modo, percebemos através das falas apresentadas uma efetiva preocupação por parte dos policiais militares na realização de AF, objetivando além do fator saúde que permeia todo este estudo, fatores ligados ao lazer e a capacitação física para a atividade laboral.

Nesta perspectiva, observamos uma estreita ligação entre a atividade laboral e os hábitos de prática dos indivíduos, caracterizando a AF como essencial para o cumprimento eficiente da missão policial. Corroborando assim com a literatura apresentada por Silva (2012, p. 13), que relata: “o policial militar, como sendo agente de segurança pública, deve estar apto a perseguições, seja com viaturas, motos, cavalos ou a pé. E por isso precisa ter maior atenção ao seu condicionamento físico, principalmente força e aptidão cardiorrespiratória".

Dentre as diversas modalidades de práticas relatadas, destacaram-se a musculação com $n=15$ (33\%), a corrida com $\mathrm{n}=13(28 \%)$, a caminhada com $\mathrm{n}=7$ (15\%) e as lutas englobando Muai Thay, Jjiu-Jitsu e Judô com n=4 (9\%) das respostas obtidas. Outras modalidades como: Ciclismo, Cooper, Futebol, Natação e Surfe apresentaram uma adesão mais discreta quanto às demais. Ao analisarmos os fatores motivacionais relacionando-os as práticas escolhidas pelos respondentes, constatamos que para os indivíduos cuja a saúde foi alegado como fator motivacional, as práticas de musculação e a corrida são as atividades mais praticadas apresentando cada uma delas um $n=15$ (37\%), seguido pela caminhada com $n=7(17 \%)$ das respostas. Já os que alegaram a estética como fator motivacional, a atividade musculação foi a mais mencionada com $n=6(55 \%)$, a corrida apresentou um $n=4(36 \%)$ e as lutas $n=1(9 \%)$ das respostas.

Observamos que as atividades que priorizam a utilização do sistema cardiorrespiratório, os ditos aeróbicos, destacaram-se na escolha dos entrevistados com $\mathrm{n}=35$ (76\%) das respostas, estes exercícios também apresentam-se como de fácil acessibilidade e reduzido custo como é o caso da corrida de rua e caminhada.

Ao discorrer sobre o tempo que o indivíduo tem de prática, bem como a frequência em que esta atividade é realizada, foi observado que um $n=12(43 \%)$ da amostra pratica AF há pelo menos 
4 anos, já $n=10(35 \%)$ afirmou entre 1 e 3 anos de prática, enquanto $n=6(22 \%)$ responderam ter dado início a esta prática há menos de 1 ano. Quanto à frequência semanal $n=19(73 \%)$ dos respondentes relataram uma assiduidade de 3 ou mais dias de prática. Já os que praticam 2 dias na semana representam um $n=6(23 \%)$, enquanto $n=1(4 \%)$ dedicam apenas 1 dia da semana para a realização de AF.

Por intermédio das respostas obtidas, pudemos observar um satisfatório índice de adesão às práticas de AF, bem como da frequência semanal e engajamento na realização de tais práticas. Vale salientar que de acordo com a Organização Mundial de Saúde (OMS), as recomendações para a prática de AF para adultos saudáveis são de pelo menos 150 minutos semanais de atividades leves ou moderadas; ou 75 minutos semanais de atividades consideradas mais intensas, sendo preferencialmente distribuídas em uma frequência recomendada de 30 minutos diários (WORLD HEALTH ORGANIZATION, 2020).

Quando questionado sobre a companhia para a prática de AF, observamos que $n=19(44 \%)$ das respostas indicam a realização de tais práticas individualmente, enquanto $n=9(21 \%)$ relatam a prática na presença de amigos, um $n=8(19 \%)$ é referente à realização das AF com familiares e apenas $\mathrm{n}=7$ (16\%) alegam a realização de AF com a presença de um profissional habilitado. Dois dados nos chamam a atenção, a alta incidência na prática individual, e o baixo número de militares que utilizam a ajuda de um profissional de Educação Física para a realização de atividades físicas.

Sobre a temática da adesão de forma individual às AF, os estudos realizados por Reis (2001), destacam que há uma interferência socioambiental nos estímulos à prática de AF, sobretudo afirmando a importância do incentivo dos amigos e familiares na adesão e engajamento das práticas. Neste sentido a coletividade para a prática de AF tende a manter os indivíduos motivados por mais tempo. Contudo, devemos levar em consideração que as escalas de serviço dos militares nem sempre são compatíveis com as demais profissões, exigindo do profissional muitas vezes uma flexibilidade nos horários, o que nem sempre favorece a companhia para a prática.

Quanto à não realização das práticas com auxílio de um profissional habilitado, de acordo com Freitas (2013), há um grande risco de lesões agudas e crônicas que permeiam esta prática não assistida, do mesmo modo que podemos observar a possibilidade da não eficácia das AF para o êxito nos objetivos pré-estabelecidos pelos sujeitos da pesquisa em suas práticas, sejam eles saúde, estética ou condicionamento físico.

Ao questionar sobre os locais de prática dos sujeitos observamos que a maioria, ou seja, $\mathrm{n}=18(55 \%)$ das respostas indicam que os militares costumam praticar suas atividades ao ar livre, em locais propícios e agradáveis para o desenvolvimento de tais práticas como praças, avenidas menos movimentadas e na orla, seja pelo fácil acesso destes ambientes públicos e/ou a não 
necessariedade da disponibilização de recursos financeiros para a utilização destes espaços. Entretanto, $n=16(42 \%)$ das respostas indicam as academias de musculação e artes marciais como locais de prática e apenas $n=1(3 \%)$ afirmam a realização das práticas no quartel. Neste sentido observamos um déficit por parte da corporação em oferecer um local propício e atrativo para a realização de atividades físicas, tendo em vista que, se ao iniciar a jornada de trabalho o militar tem a sua disposição uma academia de musculação ou um dojô com um instrutor habilitado, teríamos um dia a mais de prática para os já praticantes e um incentivo para os que ainda não realizam tal atividade, elevando os índices de adesão e hábitos de prática das AF,o mesmo se aplica para a prática de defesa pessoal e artes marciais, contribuindo também para a capacitação técnica do policial militar.

\section{Satisfação Relacionada à Imagem Corporal e as Práticas de AF}

Ao questionar a respeito da satisfação sobre a imagem corporal neste estudo, foi possível observar que $\mathrm{n}=17$ (53\%) da amostra não se encontram satisfeitos com sua imagem corporal. Ao analisar as respostas provenientes das questões abertas sobre o tema, observamos que o motivo de insatisfação de maior predominância é o excesso de gordura, principalmente abdominal, o que acarreta num quadro de excesso de peso dos militares, fatores provenientes muitas vezes do próprio serviço policial militar como a inatividade física, hábitos de alimentação prejudiciais à saúde e a falta de qualidade do sono, bem como a não realização de atividades físicas orientadas por um profissional habilitado, uma vez que apenas $n=7$ (16\%) das respostas indicam que os militares buscam um instrutor formado para a realização de exercícios físicos, exercem influência na imagem corporal dos entrevistados.

Nesta perspectiva, através do cálculo conforme a ABESO (2016) do Índice de Massa Corporal $^{3}$ (IMC) dos participantes foi possível observar que, $\mathrm{n}=16(50 \%)$ da amostra encontra-se numa situação de sobrepeso ou pré-obesidade, enquanto $n=9(28 \%)$ dos entrevistados está inserido num quadro de obesidade grau I, II ou III. Já n=7 (22\%) estão em uma situação de peso normal. Por conseguinte, a busca pelos padrões estéticos ideais, também aparecem como motivação para a insatisfação corporal dos militares. Tais dados evidenciam-se nas seguintes afirmações:

[...]Não estou satisfeito, preciso de exercícios físicos para diminuir a gordura corporal[...] (Suj.2).

[...]Tenho a necessidade de baixar 5 quilos para entrar no IMC ideal[...] (Suj.7).

${ }^{3}$ Classificação internacional da obesidade conforme IMC, de acordo com as diretrizes da ABESO (2016):

$(<18,5)$ Magro ou baixo peso; $(18,5$ - 24,9) Normal ou eutrófico; $(25-29,9)$ Sobrepeso ou pré-obeso; $(30-34,9)$

Obesidade grau I; $(30-39,9)$ Obesidade grau II; $(\geq 40,0)$ Obesidade grave ou grau III. 
[...]Gostaria de ter menos gordura e mais músculos, mas posso melhorar[...] (Suj.22).

[...]Estou acima do peso e com a barriga saliente[...] (Suj.30).

O termo satisfação ou insatisfação geralmente está atrelado a um processo de avaliação ou julgamento de uma experiência particular, através de parâmetros individuais e subjetivos que determinam a realização das expectativas e desejos pessoais do indivíduo (KOTLER, 2006).

Quando tratamos sobre a imagem corporal Reichert, Silva e Brunetto (2010, p.171) relatam que "a imagem corporal abrange dimensões fisiológicas, psicológicas e sociais, sendo composta por representações sobre aparência, tamanho e forma corporal". Sendo assim, a compreensão da imagem corporal está correlacionada ao processo de satisfação do indivíduo consigo mesmo e o ambiente que o cerca.

A busca pelo estereótipo corporal ideal, imposta muitas vezes pela grande mídia, sem a devida orientação profissional gera uma série de danos à saúde, sobretudo quando há a utilização de dietas e produtos ergogênicos de forma equivocada e relapsa (FREITAS, 2013).

Contudo, os outros $n=15$ (47\%) da amostra que afirmaram estar satisfeitos com a sua imagem corporal, agregam a este sentimento características como a capacidade física/portefísico, o estado de saúde e o peso corporal. Deste modo, observamos que há uma associação entre as medidas antropométricas e a satisfação/insatisfação da imagem corporal dos indivíduos participantes desta pesquisa, sendo a incidência de maior tecido adiposo, bem como a necessidade de hipertrofia muscular, fatores preponderantes para a insatisfação. Porém, como supracitado a imagem corporal abrange diversas perspectivas, tanto objetivas quanto subjetivas. Desta forma, de acordo com Souza (2017), devemos levar em consideração ao analisar esta temática, outros aspectos que transcendem os limites antropométricos, como por exemplo: o sexo dos participantes e os valores culturais que influenciam no processo de construção corporal, da prática de atividades física e nutricional dos indivíduos.

Ao questionar a respeito da satisfação proporcionada pela prática de AF, encontramos um $\mathrm{n}=21(70 \%)$ da amostra que afirmaram estar satisfeitos com a sua rotina de exercícios físicos, levando em consideração as respostas obtidas através dos questionamentos abertos realizados, observamos que o sentimento de satisfação advém das benéfices proporcionadas por esta prática, tais como: o bem-estar, a manutenção da saúde e da boa forma física, a disposição físicae a autoestima. O que podemos comprovar nas seguintes falas:

[...]Sim estou satisfeito, por causa dos retornos salutares que elas me proporcionam, pois a capacidade física pode ser fator determinante em muitas circunstâncias de nossa atividade[...] (Suj.10).

[...]Observei melhoras físicas, respiratórias e da resistência.[...] (Suj.17). 
[...]Por causa da atividade física me sinto menos preguiçoso, com mais disposição[...] (Suj.27).

Conforme a literatura descrita por Correa (2019), a prática regular e orientada de AF é uma eficiente intervenção no que se refere a melhora da qualidade de vida dos praticantes, fato este de suma importância para o indivíduo, trazendo para sua vida benefícios que transcendem o campo da saúde, perpassando para o aspecto sociocultural e psicológico.

Entretanto um $n=9(30 \%)$ dos militares que alegaram insatisfação na prática de atividade física informaram os seguintes fatores: a falta de tempo proveniente da própria rotina militar, o que implica negativamente na frequência e assiduidade dos militares; a falta de dedicação aos treinos; e a baixa intensidade da prática realizada pelos voluntários da pesquisa, transparecem assim como aspectos de descontentamento na rotina de realização das atividades físicas. Estes aspectos evidenciam-se nas seguintes falas:

[...]Se houvesse condições favoráveis e tempo, com certeza me dedicaria mais às atividades físicas[...] (Suj.26).

[...]Não estou satisfeito porque deveria ser mais constante e intenso[...] (Suj.1).

[...]Preciso aumentar a intensidade aliada a uma boa alimentação[...] (Suj. 7).

A respeito da intensidade e sua relação com a satisfação, Catanho $(2019$, p. 37) afirma que “das diversas variáveis agudas que podem ser manipuladas na rotina do treinamento físico [...], a intensidade e o volume dos esforços são aqueles que possivelmente exercem a maior influência nos resultados adaptativos, sejam estes de ordem funcional ou morfológica." Desta forma, podemos concluir através das falas dos sujeitos que a não obtenção dos resultados proveniente da falta de intensidade durante a AF é um fator de insatisfação dos praticantes quanto a sua rotina de práticas de AF. Ao observarmos as falas dos sujeitos 1 e 26, percebemos os termos "tempo" e "constante" e as lacunas no cotidiano dos dois sujeitos acerca do tempo e frequência, indo de encontro às recomendações da Organização Mundial da Saúde, que preconiza uma distribuição de 30 minutos diários. Os fatores tempo e frequência aqui demonstram dois aspectos importantes e fundamentais para a adesão e permanência para a dedicação às práticas de AF.

Observamos que mesmo havendo um elo que envolve a profissão militar e as práticas de atividades físicas, ainda existem barreiras e paradigmas a serem ultrapassados para uma melhora na qualidade de vida dos militares. A falta de tempo imposta pela rotina destes profissionais, aliada ao cansaço gerado pela carga horária exercida, configuram-se como verdadeiros vilões no combate à inatividade física. Contudo, observamos também que a própria corporação tem uma parcela de responsabilidade neste panorama. É o que percebemos na seguinte argumentação: 
[...]O Estado não proporciona meios compensatórios para o militar dispor de seu repouso para a prática de atividade física[...] (Suj.2).

Neste contexto, é perceptível que há uma falta de incentivos no que se refere às práticas de atividades físicas voltado de forma específica, para o profissional que atua na modalidade de rádio patrulhamento, que lhe conduza não somente a exercer melhor suas funções, mas que leve em consideração promover um salto qualitativo no quadro de saúde deste indivíduo.

\section{CONSIDERAÇÕES FINAIS}

No decorrer desta pesquisa foi possível constatar que a maioria dos militares entrevistados são adeptos de alguma prática de AF, do mesmo modo percebem-se motivados para a realização de tais práticas, contribuindo para uma melhora no que se refere à qualidade de vida destes sujeitos. Entretanto, pudemos observar que a própria profissão policial militar impõe algumas barreiras que dificultam e até mesmo impedem a prática de AF com regularidade ou da forma que o policial gostaria que fosse praticada.

Diferentes aspectos foram destacados quando indagamos a respeito do fator motivacional que conduz os militares para a prática das AF, tais como: saúde, bem-estar, qualidade de vida, estética, afeto pela prática, condicionamento físico e competições esportivas. Verificamos que existe uma preocupação por parte dos policiais em manter-se fisicamente ativos como estratégia para a manutenção e promoção da saúde, bem como da aptidão física voltada para a atividade laboral, utilizando as diversas modalidades de AF descritas neste estudo como ferramenta para superação das adversidades impostas pela rotina de trabalho e adesão a um estilo de vida saudável.

Entretanto, constatamos que há um grande índice de policiais acima do peso o que resulta em um quadro de insatisfação com a imagem corporal dos sujeitos da pesquisa. Quanto à satisfação com a rotina de exercícios realizados pelos policiais, a maioria dos entrevistados relatou estar satisfeita com a sua prática, resultado dos benefícios proporcionados pela manutenção deste hábito. Já os que se compreendem insatisfeitos relatam uma série de barreiras que são impostas pela própria instituição, além de fatores como a falta de intensidade física durante a prática.

Este estudo assim como outras literaturas referentes ao tema, AF e a profissão policial militar, destacam as problemáticas que envolvem o público alvo e a prática das $\mathrm{AF}$, sobretudo quando não há o incentivo por parte da instituição em questão. Da mesma forma evidencia a importância da manutenção e preservação das capacidades físicas, mentais, do bem-estar e qualidade de vida destes e de tantos outros profissionais.

Neste sentido, faz-se necessário a ênfase no debate a respeito da importância da prática regular de AF nos mais diferenciados âmbitos da nossa sociedade, com intuito de alertar e 
esclarecer sobre os diversos benefícios, tanto na prevenção quanto no combate das doenças crônicodegenerativas, contribuindo assim para a elaboração de planos e medidas que influenciarão positivamente nos índices de realização das práticas de AF.

Propomos que para trabalhos futuros, sejam avaliados os aspectos motivacionais com relação às práticas da $\mathrm{AF}$ dos militares pertencentes aos batalhões de policiamento especializado, os quais dispõem de AF de forma obrigatória em sua rotina de serviço, comparando-os aos militares do policiamento convencional e refletindo acerca dos hábitos de práticas, características antropométricas e a qualidade de vida entre tais policiais.

\section{REFERÊNCIAS}

BARDIN, Laurence. Análise de conteúdo. Lisboa: Edições 70, 1977.

BERGAMINI, Cecília Whitaker. Motivação nas organizações. 4ª ed. São Paulo: Atlas, 1997.

CASPERSEN, Carl; POWELL, Kenneth; CRISTENSEN, Gregory. Physical activity, exercise and physical fitness: definitions and distinctions for health-related research. Public Health Reports Atlanta - E.UA.v. 100, n. 2, 126-131, abr. 1985. Disponível em: https://www.ncbi.nlm.nih.gov/pmc/articles/PMC1424733/pdf/pubhealthrep00100-0016.pdf.Acesso em: 12 jun. 2019.

CATANHO, Fernando. O papel da intensidade e do volume na prescrição do exercício e os impactos na prescrição nutricional. Revista Brasileira de Nutrição Funcional, [s.1.], v. 44, n. 79, p. 36-45, 2019. Revista Brasileira de Nutrição. Disponível em: https://www.vponline.com.br/portal/noticia/pdf/f7a440e33341094988f48d6cf0f1c4b8.pdf. Acesso em: 20 jun. 2020.

CORREA, Regina. Saúde mental e exercício físico: ingredientes para uma vida melhor. 2019. $84 \mathrm{f}$. Trabalho de conclusão (Mestrado Profissional em Exercício Físico na Promoção da Saúde). Universidade Pitágoras Unopar, Londrina: [s.n], 2019. Disponível em: https://repositorio.pgsskroton.com/bitstream/123456789/23341/1/capa_preta_junto.pdf. Acesso em: 21 jun. 2020.

FARIA, Terezinha Gomes. Análise comparativa do nível de motivação intrínseca de atletas de ambos os sexos, participantes de esportes individuais e coletivos, com diferentes níveis de experiência. 2004. 94 f. Dissertação (Mestrado) - Curso de Educação Física, Departamento de Educação Física, Universidade Federal do Paraná, Curitiba, 2004. Disponível em: https://acervodigital.ufpr.br/handle/1884/24771. Acesso em: 12 jul. 2019.

FONTELLES, Mauro José; SIMÕES, Marilda Garcia; FARIAS, Samantha Hasegawa; FONTELLES, Renata Garcia Simões. Metodologia da pesquisa científica: Diretrizes para elaboração de um protocolo de pesquisa. Revista Paraense de Medicina. Amazônia, v. 23, n. 3, jul./set. 2009. Disponível em: http://files.bvs.br/upload/S/0101-5907/2009/v23n3/a1967.pdf. Acesso em: 18 jul. 2019.

FOUCAULT, Michel. Vigiar e Punir: história da violência nas prisões. Petrópolis: Editora Vozes, 1987. 
FREITAS, Washington Deleon Ferreira de. A importância do profissional de educação física na orientação da musculação. Trabalho de Conclusão de Curso. Curso de Graduação em Educação Física, UNIFOR, Minas Gerais. 2013.

GERHARDT, Tatiana Engel; SILVEIRA, Denise Tolfo. Métodos de Pesquisa. Porto Alegre: Editora da UFRGS, 2009. Disponível em: http://www.ufrgs.br/cursopgdr/downloadsSerie/derad005.pdf. Acesso em: 20 jul. 2019.

GESTÃO DE PESSOAS DA CORPORAÇÃO POLÍCIA MILITAR DA PARAÍBA. Relatório da Diretoria Gestão de Pessoas da Corporação Polícia Militar da Paraíba - novembro 2019. João Pessoa, 2019.

Relatório. Impresso.

JESUS, Gilmar Mercês de; JESUS, Eric Fernando Almeida de. Nível de atividade física e barreiras percebidas para a prática de atividades físicas entre policiais militares; Revista Brasileira de Ciências do Esporte, Florianópolis, v. 34, n. 2, p. 433-448, abr./jun. 2012.

KOTLER, Philip. Administração de marketing: análise, planejamento, implementação e controle. 12 ed. São Paulo: Pearson Prentice Hall, 2006.

MARRAS, Jean Pierre. Administração de recursos humanos: do operacional ao estratégico. $13^{\mathrm{a}}$ ed. São Paulo: Saraiva, 2010.

PITANGA, Francisco José Gondim. Epidemiologia da atividade física, exercício físico e saúde. $2^{\mathrm{a}}$ ed. São Paulo: Phorte, 2004.

REICHERT, Felipe Fossati; SILVA, Ana Júlia Batista da; BRUNETTO, Bruna Camargo. Imagem corporal de praticantes de treinamento com pesos em academias de londrina, PR. Rev. Bra. Ativ. Fís. Saúde, [s.1.], v. 15, n. 3, p.170-175, mar. 2010. Disponível em: http://cev.org.br/biblioteca/imagem-corporal-praticantestreinamento-com-pesos-academias-londrina-pr/. Acesso em: 12 jan. 2020.

REIS, Rodrigo Siqueira. Determinantes ambientais para a realização de atividades físicas de nos parques urbanos de Curitiba: uma abordagem sócio-ecológica da percepção dos usuários. 2001. $177 \mathrm{f}$. Dissertação (Mestrado) - Curso de Educação Física, Centro de Desportos, Universidade Federal de Santa Catarina, Curitiba, 2001. Disponível em: https://repositorio.ufsc.br/handle/123456789/80235?show=full. Acesso em: 22 fev. 2020.

SCHWAAB, Debora Regina. Motivação intrínseca e extrínseca nas aulas de educação física. 2014.52 f. Trabalho de Conclusão de Curso (Licenciatura) - Curso de Graduação em Educação Física, UNB, Primavera do Leste, 2014.

SILVA, Jocélio Monteiro. Segurança Pública Ativa: avaliação do vo2 máx. dos ciclo patrulheiros do $2^{\circ}$ batalhão de polícia militar do estado da Paraíba (BPM-PB). 2012. 32 f. Trabalho de Conclusão de Curso (Licenciatura Plena) - Curso de Graduação em Educação Física, UEPB, Campina Grande, 2012. Disponível em: http://dspace.bc.uepb.edu.br/jspui/bitstream/123456789/949/1/PDF\%20-

\%20Joc\%C3\%A9lio\%20Monteiro\%20da\%20Silva.pdf. Acesso em: 01 nov. 2019.

SILVA, Lauro Márcio Osório da. Hábitos de vida e o nível das atividades físicas realizadas pelos policiais militares que compõem o $5^{\circ}$ batalhão de polícia militar. Revista Científica de Pesquisa em Segurança Pública, [s.1.], v. 14, n. 1, p.120-135, jun. 2015. Disponível em:

http://revistacientifica.pm.mt.gov.br/ojs/index.php/semanal/article/view/257/pdf_156. Acesso em: 05 fev. 2020.

SILVA, Luimaykell Ribeiro; OLIVEIRA, Edina Araújo Rodrigues; LIMA, Luisa Helena Oliveira; FORMIGA, Laura Maria Feitosa; SOUSA, Antônia Sylca de Jesus; SILVA, Raylanne Nunes. Fatores de risco para hipertensão arterial em policiais militares do centro-sul piauiense. Revista Baiana de Saúde 
Pública, [s.1.], v. 38, n. 3, p.679-692, fev. 2014. Secretaria da Saúde do Estado da Bahia. Disponível em: http://rbsp.sesab.ba.gov.br/index.php/rbsp/article/view/707. Acesso em: 25 ago. 2019.

SOUZA, Aline Cavalcante de. Relação entre atividade física, corpo e imagem corporal entre universitários da Argentina, Brasil, Estados Unidos da América e França. 2017. 202 f. Dissertação (Mestrado em Ciências) - Faculdade de Saúde Pública da Universidade de São Paulo. São Paulo, 2017. Disponível em:https://www.teses.usp.br/teses/disponiveis/6/6138/tde-02082017-

153802/publico/AlineCavalcanteSouzaRevisada.pdf. Acesso em: 08 fev. 2020.

WORLD HEALTH ORGANIZATION. Global recommendations on physical activity for health. Genebra: WHO. Disponível em: https://www.who.int/dietphysicalactivity/pa/en/. Acesso em 16 jun. 2020.

YANNOULAS, Silvia Cristina (Coord.). Trabalhadoras: Análise da Feminização das Profissões e Ocupações. Brasília: Abaré, 2013.

ZAMAI, Carlos Aparecido; BANKOFF, Antônia Dalla Pria. Atividade física e Saúde: Experiências BemSucedidas nas Empresas, Organizações e Setor público. Jundiaí, Paco Editorial: 2013.

\section{NOTAS DE AUTOR}

\section{AGRADECIMENTOS}

Ao $5^{\circ}$ Batalhão de Policia Militar, bem como a todos os seus componentes, por toda a ajuda e disponibilidade ofertadas, viabilizando a elaboração deste estudo.

FINANCIAMENTO - Não se aplica.

CONSENTIMENTO DE USO DE IMAGEM - Não se aplica.

\section{APROVAÇÃO DE COMITÊ DE ÉTICA EM PESQUISA}

O presente estudo obteve aprovação do Comitê de Ética do Centro de Ciências Médicas da Universidade Federal da Paraíba, através do Parecer $n^{0}: 3.686 .896$, com número de processo no CAAE: 21625219.9.0000.8069, na data de 06 de novembro de 2019, seguindo de acordo com a norma 466\2012 CNS/CONEP, que diz respeito à condição de dignidade e autonomia humana em relação a pesquisas com seres humanos através do consentimento e assinatura do termo de aceitação livre e esclarecido por parte dos participantes desta pesquisa.

\section{CONFLITO DE INTERESSES - Não se aplica.}

\section{LICENÇA DE USO}

Os autores cedem à Motrivivência- ISSN 2175-8042 os direitos exclusivos de primeira publicação, com o trabalho simultaneamente licenciado sob a Licença CreativeCommonsAttribution NonComercial ShareAlike (CC BY-NC SA) 4.0 International. Esta licença permite que terceiros remixem, adaptem e criem a partir do trabalho publicado, desde que para fins não comerciais, atribuindo o devido crédito de autoria e publicação inicial neste periódico desde que adotem a mesma licença, compartilhar igual. Os autores têm autorização para assumir contratos adicionais separadamente, para distribuição não exclusiva da versão do trabalho publicada neste periódico (ex.: publicar em repositório institucional, em site pessoal, publicar uma tradução, ou como capítulo de livro), com reconhecimento de autoria e publicação inicial neste periódico, desde que para fins não comerciais e compartilhar com a mesma licença.

\section{PUBLISHER}


Universidade Federal de Santa Catarina. Programa de Pós-Graduação em Educação Física. LaboMídia - Laboratório e Observatório da Mídia Esportiva. Publicado no Portal de Periódicos UFSC. As ideias expressadas neste artigo são de responsabilidade de seus autores, não representando, necessariamente, a opinião dos editores ou da universidade.

\section{EDITORES}

Mauricio Roberto da Silva, Giovani De Lorenzi Pires, Rogério Santos Pereira.

\section{HISTÓRICO}

Recebido em: 05 de maio de 2020.

Aprovado em: 28 de junho de 2020. 